\title{
Elisabetta Longhi (dir.). The Nine Domes of the Universe. The Ancient Noh Gonbad Mosque. The Study and Conservation of an Early Islamic Monument in Balkh
}

\section{Sandra Aube}

\section{OpenEdition}

\section{Journals}

Édition électronique

URL : http://journals.openedition.org/abstractairanica/42692

DOI : 10.4000/abstractairanica.42692

ISBN : 1961-960X

ISSN : 1961-960X

Éditeur :

CNRS (UMR 7528 Mondes iraniens et indiens), Éditions de l'IFRI

\section{Référence électronique}

Sandra Aube, «Elisabetta Longhi (dir.). The Nine Domes of the Universe. The Ancient Noh Gonbad Mosque. The Study and Conservation of an Early Islamic Monument in Balkh », Abstracta Iranica [En ligne], Volume 37-38-39 | 2018, document 15, mis en ligne le 10 mars 2018, consulté le 27 septembre 2020. URL : http://journals.openedition.org/abstractairanica/42692 ; DOI : https://doi.org/10.4000/ abstractairanica.42692

Ce document a été généré automatiquement le 27 septembre 2020

Tous droits réservés 


\title{
Elisabetta Longhi (dir.). The Nine Domes of the Universe. The Ancient Noh Gonbad Mosque. The Study and Conservation of an Early Islamic Monument in Balkh
}

\author{
Sandra Aube
}

\section{RÉFÉRENCE}

Elisabetta Longhi (dir.). The Nine Domes of the Universe. The Ancient Noh Gonbad Mosque. The Study and Conservation of an Early Islamic Monument in Balkh, Kabul/New York/ Lurano/Bergamo : Aga Khan Trust for Culture/Délégation Archéologique Française en Afghanistan (DAFA)/World Monuments Fund/Associazione Giovanni Secco Suardo/ Bolis Edizioni, 2016, 284 p., suivi de 100p. en Persan, nombreuses ill. couleur. ISBN : 978-88-909038-3-0

1 Cet important volume collectif, édité à l'instigation de l'Aga Khan Trust for Culture, fait le bilan des principaux travaux effectués sur la mosquée Noh Gonbad, à Balkh, à l'occasion de travaux de restauration menés sur le site.

2 L'ouvrage s'ouvre sur une introduction de Lisa Golombek («Between Balkh (Noh Gonbad) and Isfahan ", p. 35-45), au cours de laquelle l'auteure revient sur certains des arguments et datations proposés plus de quarante années auparavant dans l'article qu'elle fit paraître sur la mosquée (voir infra). Son introduction s'ouvre comme une réponse aux arguments développés par Adle dans son article sur Noh Gonbad paru en 2011 (voir infra). Golombek admet une datation des stucs de Noh Gonbad antérieure à Sāmarrā et, à travers un argumentaire précis, rapproche l'édifice de la mosquée abbasside d'Isfahan, pour laquelle elle propose une datation comprise entre 772 et 840 . 
Une série de contributions suit cette introduction. Le premier article est co-signé par les archéologues de la Délégation Archéologique Française en Afghanistan (DAFA, Kaboul) associés aux fouilles archéologiques menées sur le site : Philippe Marquis, Julio Bendezu Sarmiento, Thomas Lorain et Nader Rassuli ( Noh Gonbad: Works Carried out by the French Archaeological Delegation », p. 49-59). Après un rappel historique de la longue implication de la DAFA sur le site de Noh Gonbad, les auteurs proposent une analyse topographique $\mathrm{du}$ site, puis offrent une introduction aux travaux archéologiques en cours sur la mosquée, en restituant notamment les différentes séquences chronologiques d'ores-et-déjà observables.

Cet article est suivi par un libre essai d'Assadullah Souren Melikian-Chirvani ( $"$ The Nine Domes of the Universe », p. 61-73). Trois articles font ensuite état des travaux de restauration entrepris sur le site, de leurs enjeux, des techniques mises en œuvres et des analyses effectuées à cette occasion: Arash Boostani, Ugo Tonietti, «History and Crucial Aspects of Strengthening the Arch System» (p.75-121), Fabio Fratini, "Characteristics of the Various Building Materials Used in the Noh Gonbad Mosque in Balkh» (p. 123-131), and Nathalie Bruhière, Daniel Ibled, Fanny Kurzenne, «Consolidations of the Stuccoes at Noh Gonbad in Balkh » (p. 133-149).

En annexe, ce volume propose d'intéressants outils pour l'étude de la mosquée Noh Gonbad, à savoir: le relevé 3D de l'édifice ; un dossier photographique, comprenant notamment les photographies prises par Josephine Powell entre 1958 et 1971 ; et enfin la reproduction des articles publiés par Galina A. Pougatchenkova en 1968 ( monuments peu connus de l'architecture médiévale de l'Afghanistan ", Afghanistan, XXI, no. 1), Lisa Golombek en 1969 ("Abbassid Mosque at Balkh», Oriental Art, XV, no. 3) et l'article, plus récent, que publiait Chahryar Adle en 2011 («La mosquée HâjiPiyâdah/Noh-Gonbadân à Balkh (Afghanistan). Un chef de Fazl le Barmacide construit en 178-179/794-795?

", Comptes rendus de l'Académie des Inscriptions, no. 1). L'ensemble s'achève sur la traduction en Dari de toutes les contributions.

En faisant dialoguer les différents points de vue, en restituant l'historiographie des travaux menés sur le site, et en offrant un panel de photos, coupes, plans et analyses diverses, ce livre constitue ainsi une ressource importante sur la mosquée Noh Gonbad de Balkh. Souhaitons qu'un volume complémentaire, de même facture, puisse prochainement présenter plus avant les travaux archéologiques en cours.

\section{AUTEURS}

\section{SANDRA AUBE}

CNRS, Mondes iranien et indien, Paris 